\title{
The Dominance of Microcystis Species and Microcystin Congeners in a Small Holder Fish Farm, a Case Study of Vhembe District, South Africa
}

\author{
J.R. Gumbo and A.R. Tshifura
}

\begin{abstract}
The aim of the study was to investigate the presence of cyanobacteria in a small holder fish farm, Limpopo province, South Africa.The water samples were collected at random from the two aquadams. A Multimeter instrument, ion chromatographic method and High-performance liquid chromatography (HPLC)-UV detector was used to determine the physical-chemical quality of the pond water. The FlowCAM captured images of cyanobacteria species and were then compared with published images to identify the cyanobacteria. The single factor single factor ANOVA was used to determine relationship among microcystin congeners within the aquadams, across the months at $p<0.05$. The water quality was alkaline, with water temperatures in range of 27.7 to $30.0{ }^{\circ} \mathrm{C}$, electrical conductivity range of 31.5 to $110.4 \mu \mathrm{S} / \mathrm{cm}$ and total dissolved solids range of 20.28 to $70.6 \mathrm{mg} / \mathrm{l}$, soluble phosphates (nil) and nitrate range 0.312 to $0.440 \mathrm{mg} / \mathrm{l}$. The Microcystis, Anabaena, and Oscillatoria species were identified in the aquadams. The microcystin RR congener was absent. The microcystin LR, dominant, was present throughout the study period and in all the aquadams in range of 6.17 to $732.58 \mu \mathrm{g} / \mathrm{l}$ and was significant across the months $(p=0.02)$ and insignificant among the aquadams $(p=0.20)$. For microcystin congeners such $Y R$ and $L Y$ their concentrations were rather limited with single factor ANOVA indicating that the microcystin congeners was not significant different $(p=0.19)$. The aquadams are best habitat for cyanobacteria and microcystins, which may be hazardous to humans who may consume the tilapia fish.
\end{abstract}

Keywords - microcystin LR; Oreochromis mossambicus (tilapia); aquaculture; human health.

\section{INTRODUCTION}

Aquaculture or fish farming is on the increase worldwide including South Africa ${ }^{1}$. Thus the harvested fish may be a source of protein (readily available food) and the generation of incomes as a poverty reduction strategy [1]. In order to improve fish productivity per unit water volume, there is deliberate excessive addition of fertilizer and fish feed[2-3]. The study of Smith et al.[3] in the Mississippi fish farms, United States of America showed a massive addition of $32 \%$ protein fish feed of $150 \mathrm{~kg} / \mathrm{ha}$ directly contributed to $1 \mathrm{mg}$ of dissolved nitrogen $(\mathrm{N})$

J.R. Gumbo is with the University of Venda, Department of Hydrology \& Water Resources.

A.R. Tshifura was a postgraduate student with University of Venda . per litre per day. However the presence of excess nutrients in the freshwater ecosystems and suitable climatic conditions (high solar radiation, high temperatures) leads to the rapid growth of cyanobacteria and the formation of dense harmful algal blooms (HABs) and the production of cyanotoxins and metabolites [2-3]. A study by Jewel et al.[2] in a small fish holder farm in Pakistan showed that a high rate application of fertilizer and fish feed to the fish ponds, during the summer period, directly contributed to the growth of HABs. Thus the presence of HABs in the fish ponds probably contributed to massive fish mortalities among the silver and common carp, tilapia and catla fish species ${ }^{3}$. The fish mortalities were probably due to oxygen deprivation and cyanotoxin poisoning.

The oxygen deprivation was due to the decaying and decomposition of HABs[4]. The cyanotoxin poison, as shown by high cyanobacterial cells in fish gut contents, and gill clogging was attributed to the presence of cyanobacterial species namely: Aphanizomenon flos-aquae Ralfs and Microcystis aeruginosa $\mathrm{Kutz}^{3}$. The microcystins in which there are over 80 congeners are produced by dominant cyanobacteria genera Microcystis aeruginosa and Anabaena spp., Oscillatoria spp., Aphanizomenon spp [5]. The cyanobacterium, Microcystis aeruginosa, was identified as the producer of microcystin-LR that was found in fish ponds after massive catfish (Ictalurus punctatus) mortalities [6]. In South Africa, there are limited studies on cyanotoxin analysis of fish pond water even though they are active promotion of aquaculture development by South African government [7]. The main objective of this study is to draw attention to the occurrence of dominate Microcystis aeruginosa and microcystin-LR in an aquadams in a small holder Tilapia fish farm in Itsani village, Vhembe district, Limpopo province of South Africa. In this study, there were no Tilapia (Oreochromis mossambicus) fish mortalities at the fish farm.

\section{MATERIALS AND METHODS}

\section{A. The location of the study area}

The study area was Itsani Matieni in Limpopo province of South Africa which is located under the local Thulamela Municipality of Vhembe municipal district, Limpopo province of South Africa (Fig. 1). 


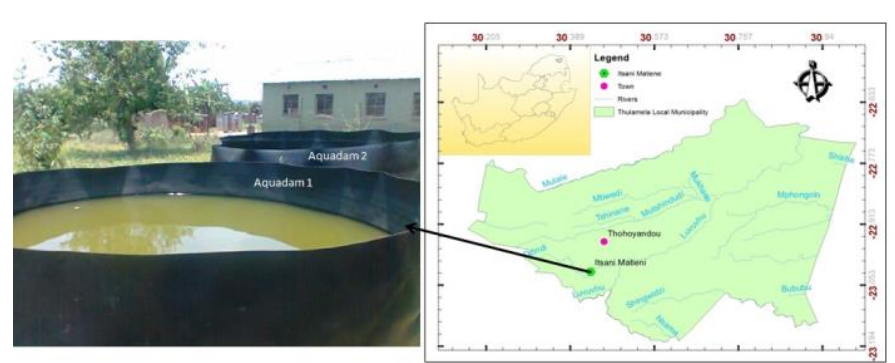

Fig. 1: The location of the study area in Itsani Matieni and the aquadams with water which is coloured green possible due to the presence of cyanobacteria.

\section{B. Sample collection:}

The water samples were collected from two aquadams from November 2012 to January 2013 (Fig.1). The water samples were collected in two different $250 \mathrm{ml}$ sampling bottles. The water samples were subdivided for physico-chemical analysis, nutrient analysis, microcystin analysis and identification of cyanobacteria species.

\section{Physico-chemical analysis}

The multi meter, Cyberscan 8H21-2 was used to measure, $\mathrm{pH}$, water temperature, total dissolve solids (TDS) and electrical conductivity (EC) after calibration as per manufacturer instructions. For the measurement of the nutrients, phosphate and nitrate, the Ion Chromatography Metrohm 850 professional IC (Metrohm, Switzerland) was used. The measurements were conducted in triplicates and the standard deviation and the mean of the concentration were calculated. The running was done under the following ion chromatographic conditions: Flow rate $0.7 \mathrm{~mL} / \mathrm{min}$; Running pressure $5.92 \mathrm{Mpa}$; Minimum pressure 0.1 Mpa; Maximum pressure $15 \mathrm{Mpa}$ and Column temperature $30^{\circ} \mathrm{C}$. The blank determination was done after running samples to make sure that there is no cross contamination. The mobile phase and the standards were prepared according to the manufacturer's instructions.

\section{Identity of cyanobacteria species in the aquadams:}

A benchtop FlowCAM (Model VS IV) was used to determine the composition of cyanobacteria species. The FlowCAM was equipped with a blue $(488 \mathrm{~nm}$ ) laser for florescent and particle detection. For the analysis of algal composition in natural field samples a flow cell (FC300) was used with $4 \mathrm{X}$ objective and a cell size range of 20 to $300 \mu \mathrm{m}$. The water samples were transferred to the funnel with a pipette. The fluorescent particle/cell was digitally acquired and archived by the FlowCAM for latter processing. The images were then compared to images found in the study of van Vuuren et al. ${ }^{8}$.

\section{E. Microcystin analysis:}

The water samples were sent to the University of Johannesburg, Johannesburg for microcystin analysis. $100 \mathrm{ml}$ of water sample was filtered through a $0.45 \mu \mathrm{m}$ membrane filter and the filtrate divided into three $10 \mathrm{ml}$ portions as per procedure of Mbukwa et al.[5]. These water samples were passed through an Oasis ${ }^{\circledR}$ HLB $3 \mathrm{cc} / 60 \mathrm{mg}$ was used for purification and cleaning. The Extracts were analysed by the Surveyor Plus ${ }^{\mathrm{TM}}$ modular LC system and the ChromQuest ${ }^{\mathrm{TM}}$ data system (Thermo Fisher Scientific San Jose, United States of America) on a $\mathrm{C}_{18}, 150 \times 4.6 \mathrm{~m}, 5 \mu \mathrm{m}$ Waters column at $30^{\circ} \mathrm{C}$ with a mobile phase composition of $60 \%$ water $+0.1 \%$ formic acid and $40 \%$ acetonitrile+ $0.1 \%$ formic acid at a flow rate of 1.0 $\mathrm{ml} / \mathrm{min}$. The Surveyor Plus modular LC system consists of the Surveyor LC Pump Plus, the Surveyor Autosampler Plus. Chromatograms at $238 \mathrm{~nm}$ were recorded with the Surveyor PDA plus Detector, and microcystins (MCYST) were identified by retention time and characteristic UV absorption spectra (200-300 nm) (Fig. 2a) and the quantification was based on external calibrations of MCYST-RR, -LR, LY and -YR, respectively (Fig 2b). The injections were in triplicate.
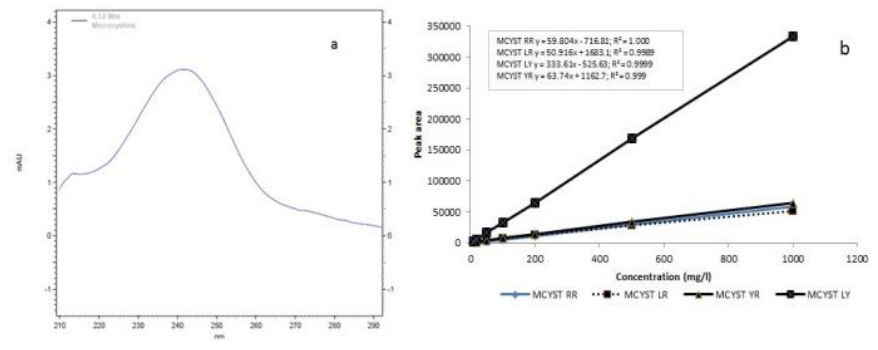

Fig. 2: (a) The characteristic UV spectrum of the sample extract during the HPLC run and (b) the external calibration of the microcystin reference standards

\section{F. Data analysis}

Data information were analysed using Microsoft excel to determine the mean, standard deviation and single factor ANOVA statistical analysis to determine any significance differences between microcystin LR concentration across months, aquadams and other microcystin congeners at $\mathrm{P}<0.05$.

\section{RESULTS AND DISCUSSION}

\section{A. Identity of cyanobacteria species in the aquadams}

The compositions of cyanobacteria communities were determined in the two aquadams (Fig. 3). The cyanobacteria communities were identified as Microcystis sp., Anabaena spp, Oscillatoria spp and Nostoc spp and these have been implicated in the production of microcystins [9]. Thus the microcystins that were found in the aquadams may have been produced by members of this Cyanophyta group. The environmental conditions, high water temperature, $\mathrm{pH}$ and the nitrates also favoured the growth and proliferation of cyanobacteria. 

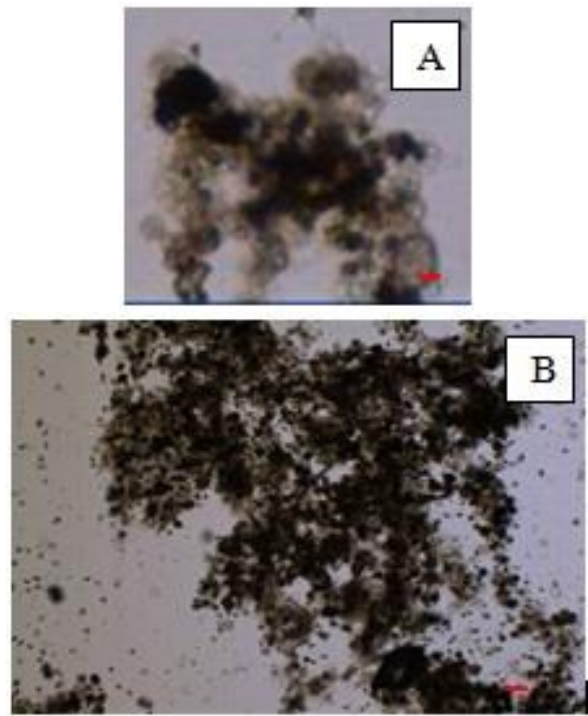

Fig. 3: The dominate Microcystis spp cyanobacteria species in: (A) aquadam 1 and (B) aquadam 2 . The $20 \mu \mathrm{m}$ scale bar is red

\section{B. Physico-chemical analysis}

The physico-chemical conditions measured from the water sample were $\mathrm{pH}$, water temperature, electrical conductivity (EC), total dissolved solids (TDS) and nitrates. The study showed that the $\mathrm{pH}$ was alkaline for both aquadams. The $\mathrm{pH}$ range may also be conducive to the proliferation of cyanobacteria [10] and conducive for the growth of Tilapia fish [11]. The presence of nitrates, ranging from 0.312 to 0.440 $\mathrm{mg} / \mathrm{l}$, was found in the aquadams. For soluble phosphates these were not detected in the water samples. The fishes were fed with the Tilapia grower pellets (brand is Farm Feed) twice a day and this may be source of nitrates in water and may contribute to proliferation of cyanobacteria communities. The tilapia grower pellets are rich in nitrates and phosphate [12]. The soluble phosphates these were not detected in the water samples. This study is consistent with the study of Ahmed et al.[13] who found that the $\mathrm{pH}$ was alkaline and absence of phosphates during a bloom occurrence at fish pond in Bangladesh.

There was variation in the water temperature during the study period but was above 27 to $30{ }^{\circ} \mathrm{C}$ which is conducive for cyanobacteria to strive well in water temperature between $15^{\circ} \mathrm{C}$ and $30^{\circ} \mathrm{C}[10]$. The water temperature range of 27.7 to $30.5^{\circ} \mathrm{C}$ was ideal for the growth of the Tilapia fish [10]. The total dissolved solids (TDS) and electrical conductivity (EC) was in the range of 20.28 to $70.6 \mathrm{mg} / \mathrm{l}$ and 31.5 to $110.4 \mu \mathrm{S} / \mathrm{cm}$ respectfully. The TDS and EC were showed a gradual decrease from November to February, 2013. This may be due to dilution in January when there was plenty of rainfall. Also the TDS and EC were ideal for the growth of the Tilapia fish [11]. A study by van Ginkel [14] showed that an EC (240 $\mu \mathrm{S} / \mathrm{cm})$ and TDS (160 $\mathrm{mg} / \mathrm{l})$ were recorded during a cyanobacterial bloom dominated by Microcystis and Pseudoanabaena in Grootdraai Dam that is situated north-east of Standerton on the Vaal River, in the Mpumalanga Province, South Africa.

\section{Microcystin analysis}

The samples were assessed on different microcystin congeners such as microcystin RR, microcystin LR, microcystin YR and microcystin LY (Table 1). For microcystin RR this was absent in all the aquadams but the dominant microcystin LR was present throughout the study period and in all the aquadams as indicated by single factor ANOVA which showed that the microcystin LR concentration was highly significant across the months $(P=0.02)$ and insignificant among the aquadams $(P=0.20)$. The dominate cyanotoxin was microcystin $\mathrm{LR}$ which was in the range of 6.17 to $732.58 \mu \mathrm{g} / \mathrm{l}$ throughout the study period. The occurrence of other microcystin congeners such YR and LY their concentrations were rather limited with single factor ANOVA indicating that the microcystin congeners were not significant different $(P=0.19)$. The high surface water temperatures $\left(>25{ }^{\circ} \mathrm{C}\right)$ also lead to proliferation of toxic Microcystis species and favour the production of microcystin-LR and RR congeners at the expense of other congeners [15]. The warm surface water temperatures may also favour the proliferation of other toxic cyanobacteria species such as the Anabaena Bory strain [16]. To the authors knowledge this is the first time to document presence of microcystins in a small holder fish farm in South Africa.

TABLE I: THE CONCENTRATIONS OF MICROCYSTINS (MC) IN THE AQUADAMS DURING NOV 2012 AND JAN 2013

\begin{tabular}{lccccc}
\hline Month & $\begin{array}{l}\text { Aquada } \\
\mathbf{m}\end{array}$ & $\begin{array}{c}\text { MC } \\
\text { RR } \\
(\boldsymbol{\mu g} / \mathbf{l})\end{array}$ & $\begin{array}{c}\text { MC } \\
\mathbf{L R} \\
(\boldsymbol{\mu g} / \mathbf{l})\end{array}$ & $\begin{array}{c}\text { MC } \\
\mathbf{Y R}\end{array}$ & $\begin{array}{c}\text { MC } \mathbf{\mu} / \mathbf{l}) \\
(\boldsymbol{\mu g} / \mathbf{l})\end{array}$ \\
\hline Nov & 1 & --- & 162.90 & 12.85 & --- \\
& 2 & --- & 732.58 & --- & 2.20 \\
Dec & 1 & --- & 6.17 & --- & --- \\
& 2 & --- & 48.95 & --- & --- \\
Jan & 1 & --- & 6.72 & --- & --- \\
& 2 & --- & 12.32 & 3.99 & --- \\
\hline
\end{tabular}

-- Not detected in the water samples

These microcystins have been reported that to cause health risk to fishes and humans and some of the symptoms were including weakness and anorexia [17]. The study of Mohamed et al. [18] showed that microcystins had the potential to accumulate in different organs of freshwater fish, Oreochromis nilotus, from a fish farm in Egypt following a cyanobacterial bloom of Microcystis aeruginosa. The World Health Organization (WHO) has established a provisional guideline value of $1.0 \mu \mathrm{g} / \mathrm{L}$ for microcystin LR in the drinking water [17]. Thus the presence of these microcystins in the aquadams has potential to contaminate the Tilapia fish and may be hazardous to humans who consume the fish [19]. A study by Mbukwa et al.[5] on the microcystin congeners, RR, LR, LY from Hartbeespoort dam, South Africa found that microcystin RR (absent in our study) was the most dominate congener instead of the potent microcystin LR. Although the microcystin congeners, YR (which contains the Tyrosine and Arginine amino acids) and LY (which contains Leucine and Tyrosine amino acids) are not regulated by $\mathrm{WHO}$ and these microcystins are still considered as toxic and hazardous to humans [20]. 


\section{CONCLUSION}

The study showed that the dominate cyanobacteria species was Microcystis spp, Anabaena spp, Oscillatoria spp, Nostoc spp and were the major producers of the microcystins which are a serious risk to fish and humans that may consume the fish. The dominant microcystin LR was present throughout the study period and in all the aquadams. The environmental conditions, high water temperature, $\mathrm{pH}$ and the nitrates promoted the proliferation of cyanobacteria. Thus further studies are required to determine the origins of cyanobacteria species in the aquadams and also develop environmental friendly methods to manage the cyanobacteria in the aquadams.

\section{ACKNOWLEDGMENT}

We would like to acknowledge the purchase of the FlowCAM with funding from the Department of Science \& Technology and National Research Fund (UID 74406) and the University of Venda (I515) for funding the study and Eskom TESP (E320) for FlowCAM equipment maintenance.

\section{REFERENCES}

[1] McCafferty, J. R., B. R. Ellender, O. L. F. Weyl, and P. J. Britz. "The use of water resources for inland fisheries in South Africa," Water SA, vol.38,pp. 327-344, 2012.

[2]Jewel, M. A. S., M. A. Affan, and S. Khan. "Fish mortality due to cyanobacterial bloom in an aquaculture pond in Bangladesh," Pakistan Journal of Biological Sciences, vol. 6, pp. 1046-1050, 2003. https://doi.org/10.3923/pjbs.2003.1046.1050

[3] Smith, Juliette L., Greg L. Boyer, and Paul V. Zimba. "A review of cyanobacterial odorous and bioactive metabolites: impacts and management alternatives in aquaculture," Aquaculture, vol. 280, pp. $5-20,2008$ https://doi.org/10.1016/j.aquaculture.2008.05.007

[4]Martins, Nathan Dias, Wilson Alves Colvara, Francisco Tadeu Rantin, and Ana Lúcia Kalinin. "Microcystin-LR: how it affects the cardio-respiratory responses to hypoxia in Nile tilapia, Oreochromis niloticus," Chemosphere, vol. 84, pp. 154-159, 2011. https://doi.org/10.1016/j.chemosphere.2011.02.016

[5]Mbukwa, Elbert A., Titus AM Msagati, and Bhekie B. Mamba. "Quantitative variations of intracellular microcystin-LR,-RR and-YR in samples collected from four locations in Hartbeespoort Dam in North West Province (South Africa) during the 2010/2011 summer season," International journal of environmental research and public health, vol. 9, pp. 3484-3505, 2012. https://doi.org/10.3390/ijerph9103484

[6]Zimba, P. V., L. Khoo, P. S. Gaunt, S. Brittain, and W. W. Carmichael. "Confirmation of catfish, Ictalurus punctatus (Rafinesque), mortality from Microcystis toxins," Journal of Fish Diseases, vol. 24, pp.41-47, 2001. https://doi.org/10.1046/j.1365-2761.2001.00273.x

[7]Aquaculture Development and Enhancement Programme, 2013 http://www.services.gov.za/services/content/Home/OrganisationServices /businessincentives/aquaculture/en_ZA (date accessed 16/12/2013).

[8]Van Vuuren, S.J., Taylor, J., Gerber, A. "A guide for the identification of microscopic algae in South Africa freshwaters". North-West University and Department of Water Affairs and Forestry, 2006.

[9]Drobac, Damjana, Nada Tokodi, Jelena Lujić, Zoran Marinović, Gordana Subakov-Simić, Tamara Dulić, Tamara Važić et al. "Cyanobacteria and cyanotoxins in fishponds and their effects on fish tissue," Harmful Algae, vol. 55, pp. 66-76, 2016.

[10] Makhera, M., J. R. Gumbo, and K. Chigayo. "Monitoring of microcystin-LR in Luvuvhu River catchment: Implications for human health," African Journal of Biotechnology, vol. 10, pp. 405-412, 2011.

[11] Department of Water Affairs and Forestry (DWAF), "South African Water Quality Guidelines" (second edition). Volume 6: Agricultural Water Use: Aquaculture, 1996.
[12] Center, W.,"Producing tilapia feed locally: a low-cost option fromsmall-scale farmers", 2009. www.worldfishcenter.org (date assessed $10 / 10 / 2013)$.

[13] Ahmed, M. S., S. Hiller, and B. Luckas. "Microcystis aeruginosa bloom and the occurrence of microcystins (Heptapeptides Hepatotoxins) from an aquaculture pond in Gazipur, Bangladesh," Turkish Journal of Fisheries and Aquatic Sciences, vol. 8, pp. 37-41, 2008.

[14] Van Ginkel, CE.,"Toxic Algal Incident in the Grootdraai Dam". Internal Report No. N/C110/02/DEQ/0401. Institute for Water Quality Studies, Department of Water Affairs and Forestry. Pretoria, 2001.

[15] Cerasino, Leonardo, and Nico Salmaso. "Diversity and distribution of cyanobacterial toxins in the Italian subalpine lacustrine district," Oceanological and Hydrobiological Studies, vol. 41, pp. 54-63, 2012. https://doi.org/10.2478/s13545-012-0028-9

[16] Oberholster, Paul J., S. Jappie, Po-Hsun Cheng, A. M. Botha, and M. W. Matthews. "First report of an Anabaena Bory strain containing microcystin-LR in a freshwater body in Africa," African Journal of Aquatic Science, vol. 40, pp. 21-36, 2015. https://doi.org/10.2989/16085914.2014.993583

[17] World Health Organization (WHO),"Toxic cyanobacteria in water", Chorus I, Bartram J, (Eds), E and FN Spoon, Routledge, London, 1999.

[18] Mohamed, Zakaria A., Wayne W. Carmichael, and Ahmed A. Hussein. "Estimation of microcystins in the freshwater fish Oreochromis niloticus in an Egyptian fish farm containing a Microcystis bloom," Environmental toxicology, vol. 18, pp. 137-141, 2003. https://doi.org/10.1002/tox.10111

[19] Hauser-Davis, Rachel Ann, Raquel Teixeira Lavradas, Ricardo Cavalcanti Lavandier, Edwin Gonzalo Azero Rojas, Alcides Wagner Serpa Guarino, and Roberta Lourenço Ziolli. "Accumulation and toxic effects of microcystin in tilapia (Oreochromis niloticus) from an eutrophic Brazilian lagoon," Ecotoxicology and environmental safety, vol. 112, pp.132-136, 2015. https://doi.org/10.1016/j.ecoenv.2014.10.036

[20] Su, Xiaomei, Qingju Xue, Alan D. Steinman, Yanyan Zhao, and Liqiang Xie. "Spatiotemporal dynamics of microcystin variants and relationships with environmental parameters in Lake Taihu, China," Toxins, vol. 7, pp. 3224-3244, 2015 https://doi.org/10.3390/toxins7083224

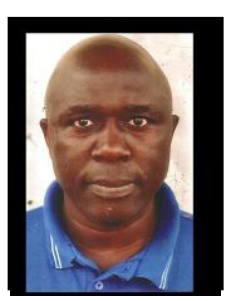

Professor Jabulani Ray Gumbo graduated with a PhD in Water Resources Management from University of Pretoria in 2007. He was awarded the second best student poster price at the $12^{\text {th }}$ International Conference on Harmful Algae in 2006 and the study was then published in the prestigious conference proceedings after a rigorous peer review process. This author became a Member (M) of International Society for the Study of Harmful Algae; International Mine Water Association; Water Institute of Southern Africa; Microscopy Society of Southern Africa and South African Council for Natural Scientific Professions. In 2008, he was appointed as a senior lecturer at University of Venda and in 2016 he was appointed as Associate Professor. $\mathrm{He}$ is the first or second author of more than 61 peer reviewed papers, conference proceedings and co-authored a chapter in a book. He acts as a reviewer for NRF in the fields of cyanobacteria and has been invited to be a reviewer for Ohio Sea Grant Proposal (USA); Journal of Applied Phycology (Australia); Bioresource Technology Journal (BITE) (USA); Journal of Freshwater Ecology (Britain); South African Journal of Science (SAJS) (South Africa) and African Journal of Biotechnology (AJB) (Nigeria), Arabian Journal of Science and Engineering (Saudi Arabia); Human Ecology (USA); Molecules, Water, Sustainability, International Journal of Environmental Research and Public Health (Switzerland), Clean-soil, air, water (USA). He lectures students at undergraduate and postgraduate levels in the fields of water treatment; water quality management; water law and institutions; rural water supply and sanitation; data information systems and water quality principles and he supervises several Honours, Masters and $\mathrm{PhD}$ students in the fields of water quality management; aquatic ecotoxicology and limnology and water treatment. He is the holder of three patents on defloridation; acid mine drainage bioremediation and removal of dyes in wastewater. 